\title{
TECNOLOGIAS LOGÍSTICAS ENVOLVIDAS NO MONITORAMENTO DO FLUXO DE REFUGIADOS NA UNIÃO EUROPEIA
}

\author{
Julia dos Santos Pitanga - SENAI CIMATEC - julia.pitanga@ba.estudante.senai.br \\ Mateus Gomes de Souza - SENAI CIMATEC - mateus.souza@ba.estudante.senai.br \\ Pedro Santos Berenguer Fernandes - SENAI CIMATEC - \\ pedro.fernandes@ba.estudante.senai.br \\ Daniel Rodrigues dos Santos (orientador) - SENAI CIMATEC - daniel.santos@fieb.org.br \\ Adriana de Carvalho Rosendo Ribeiro (coorientadora) - SENAI CIMATEC - \\ adriana.ribeiro@fieb.org.br
}

\section{RESUMO}

No panorama europeu, foi registrado o recorde de refugiados cruzando as fronteiras internacionais fugindo de conflitos, perseguições e da pobreza. Embora haja registros de pessoas encontradas na situação de refúgio na União Europeia desde os primórdios da humanidade, a logística de monitoramento dessa problemática é relativamente recente. Ademais, o objetivo deste trabalho foi analisar a eficiência das tecnologias do monitoramento do fluxo de refugiados, bem como compreender suas fragilidades logísticas no processo. Neste ínterim, as análises da logística de fluxo pessoas, bem como das tecnologias utilizadas para a vistoria da entrada de refugiados no bloco regional em questão, foi feita essencialmente através de estudos em artigos científicos e em sites de órgãos internacionais, direcionados à problemática. Os resultados obtidos mostram que apesar do sistema logístico apresentado ainda ser recente, em especial neste âmbito, com o advento de tecnologias e métodos modernos, foi possível averiguar a eficácia e potencial dessas tecnologias para o monitoramento do fluxo de refugiados na União Europeia. Neste contexto, é possível apaziguar os impasses referentes à gestão e coordenamento dos fluxos, e à reinstalação destes refugiados nos Estados-Membros pertencentes ao ACNUR (Alto Comissariado das Nações Unidas para os Refugiados), de forma a suprir as necessidades básicas de cada indivíduo. Dessa forma, pode-se concluir que as recentes imigrações de refugiados representam grandes desafios no que tange à análise e observação teórica, bem como à conjuntura legal, admitindo-se por isso que são necessários estudos mais aprofundados e novos instrumentos de monitoramento para responder à dimensão e complexidade dos fluxos.

Palavras-chave: Refugiados. Monitoramento. Fluxo. Tecnologia. Logística.

\begin{abstract}
In the European panorama, the record for refugees crossing international borders was registered fleeing conflicts, persecutions and poverty. Although there are records of people found in the refugee situation in the European Union since the dawn of humanity, the logistics for monitoring this problem are relatively recent. Furthermore, the objective of this work was to analyze the efficiency of technologies for monitoring the flow of refugees, as well as to understand their logistical weaknesses in the process. In the meantime, the analysis of the flow of people, as well as of the technologies used to inspect the entry of refugees in the regional block in question, was carried out essentially through studies in scientific articles and on websites of
\end{abstract}


international agencies, aimed at the problem. The results obtained show that although the logistical system presented is still recent, especially in this context, with the advent of modern technologies and methods, it was possible to ascertain the effectiveness and potential of these technologies for monitoring the flow of refugees in the European Union. In this context, it is possible to alleviate the impasses regarding the management and coordination of flows, and the resettlement of these refugees in the Member States belonging to UNHCR (United Nations High Commissioner for Refugees), in order to meet the basic needs of each individual. In this way, it can be concluded that the recent immigration of refugees represents great challenges in terms of analysis and theoretical observation, as well as the legal situation, assuming that it is necessary that further studies and new monitoring instruments are needed to respond to the situation dimension and complexity of flows.

Keywords: Refugees. Monitoring. Flow. Technology. Logistics.

\section{INTRODUÇÃO}

O fluxo de migrações no continente europeu, ou como foi denominada, a crise de refugiados na Europa, trata-se de um dos principais desafios que a União Europeia (UE) enfrenta na contemporaneidade. Devido ao fluxo desenfreado de imigrantes na União, que perdura desde 2011, principalmente em razão da guerra civil síria, o continente se viu obrigado a pôr à prova os mecanismos das políticas de imigração e asilo da União e a sua capacidade de responder a crises humanitárias.

No panorama contemporâneo, a relação entre as crises existentes nesses locais e a importância da logística, principalmente através do fluxo da cadeia de suprimentos ${ }^{1}$ se torna cada vez mais evidente. Mediante essa questão, denomina-se como logística humanitária é um conjunto de planejamentos e ações que visam salvar vidas, deslocar pessoas e materiais, promover o fluxo de informações e gerenciar a aquisição, a armazenagem, o transporte e a distribuição de suprimentos para atender às pessoas atingidas por desastres ou situações complexas (SAMED e GONÇALVES, 2017), fatores que indubitavelmente estão relacionados com pessoas em situação de refúgio.

Ademais, pode-se considerar como as principais portas de entrada no continente as correspondentes Grécia e Itália, uma vez que suas localizações situadas

\footnotetext{
${ }^{1}$ Conceitualmente, ela pode ser definida como um sistema de organizações, pessoas, atividades, informações e recursos envolvidos na atividade de transportar produtos ou serviços dos fornecedores aos clientes
} 
no Mar Mediterrâneo propiciam rotas mais curtas, principalmente pelo modal ${ }^{2}$ aquaviário. Nessas situações, as travessias ocorrem em embarcações precárias e superlotadas, resultando em diversos acidentes, geralmente fatais. Segundo a Organização Internacional para as Migrações (OIM), em 2016, cerca de 5 mil (5000) emigrantes faleceram ou encontram-se desaparecidos por conta da periculosidade da travessia.

Em 2017, o cenário de imigração para os Estados-Membros da União Europeia - UE - um total de 4,4 milhões de pessoas, enquanto, pelo menos, 3,1 milhões de emigrantes são dados como tendo deixado um Estado-Membro da UE (EUROSTAST, 2017). Nesse cenário, com a necessidade de monitorar o fluxo de pessoas no bloco regional, surgiu a necessidade de criar mecanismos que facilitam e integram dados de recebimentos de informações em todos os países do grupo europeu, configurando atividades logísticas de fluxo de suprimentos básicos, tornando o processo integral assim como mais transparente para análise.

Em suma, esse artigo tem por objetivo geral analisar a questão das tecnologias logísticas envolvidas no monitoramento do fluxo de refugiados geridos pela União Europeia. Ademais, busca-se especificamente identificar as principais tecnologias logísticas implementadas desde a criação da União Europeia, no que tange à questão do recebimento de refugiados, além de verificar sua eficiência ao ser executada em momentos de alto fluxo de pessoas ao continente, e por fim compreender a importância de um bom desempenho logístico na qualidade de vida das pessoas em situação de refúgio e na valorização da sua dignidade.

As fontes de informação utilizadas são os estudos fidelizados pela comunidade científica disponíveis sobre o tema, como os relatórios provenientes de organizações internacionais, tais como o Alto Comissário das Nações Unidas para os Refugiados (ACNUR) e a Comissão Europeia, e dados estatísticos dispersos. Outrossim, também se salienta o uso de artigos publicados desde 2015. Dessa forma, a evidência empírica disponível tem permitido realçar indiretamente os indivíduos como agentes reflexivos e destacar fatores políticos, econômicos e sociais que os induzem sob condições forçadas, almejando a sobrevivência, a se mover (PEREIRA, 2009).

Em suma, as migrações internacionais também aumentam no planeta e compreendem-se por diversas razões: humanitárias, sociais, econômicas e afetivas,

\footnotetext{
${ }^{2}$ A definição de modal de transporte é a maneira pela qual uma logística de produtos e pessoas é feita. Ela pode ocorrer pelas rodovias, pela água, ferrovias, por dutos ou pelo ar.
} 
independente das barreiras estabelecidas pelos países para conter esse processo. É muito comum a migração de pessoas de um país para outro, muitas vezes por meios ilegais, em busca de fontes de renda mais rentáveis e melhores oportunidades. Portanto, essa pesquisa é justificada pela necessidade de avaliar a incorporação de métodos logísticos inovadores, mais sofisticados e eficientes, na medida que o fluxo de refugiados na Europa tende a se intensificar, tornando-se imprescindível o aperfeiçoamento dos métodos de transporte, distribuição e realojamento desses refugiados nos países envolvidos.

\section{FUNDAMENTAÇÃO TEÓRICA}

Esse artigo tem como metodologia uma finalidade básica estratégica, com ênfase em produzir um conhecimento útil com valia em estudos práticos. Nesse ponto, dirigir-se um tipo de pesquisa predominantemente descritiva e explicativa com o intuito de expor as tecnologias logísticas contemporaneamente utilizadas e explicar suas funções nas operações encarregadas. Ademais, é válido ressaltar o método da abordagem usado: quantitativa ao contextualizar com dados numéricos científicos a eficiência dessas tecnologias, assim como qualitativa ao buscar a partir de uma convicção com o intuito de provocar uma reflexão acerca da eficácia desses meios.

\subsection{Logística Humanitária e Fluxo de Pessoas}

Neste capítulo são abordadas as questões da logística humanitária condizentes ao decurso do transporte e desterritorialização de refugiados, levando em conta o impacto dessas operações em sua vivência. Além disso, são salientadas as problemáticas inerentes aos processos legislativos envolvidos, bem como de que forma tais processos podem retardar a velocidade de resposta de países e órgãos beneficentes, atrasando o fluxo de pessoas.

Logística é a parte do Gerenciamento da Cadeia de Abastecimento que planeja, implementa e controla o fluxo e armazenamento eficiente e econômico de matérias-primas, materiais semiacabados e produtos acabados, bem como as informações a eles relativas, desde o ponto de origem até o ponto de consumo, com o propósito de atender às exigências dos clientes. (Carvalho, 2002, p. 31).

Nessa conjuntura, de acordo com o ilustrado acima, a logística emprega a importante função de satisfazer as necessidades de transporte, movimentação e 
manuseio de insumos, commodities e informações, sejam elas referentes a organizações corporativas, nacionais ou particulares, de modo a atender as exigências acordadas em tempo hábil e de forma correta. Ademais, a logística fundamenta-se no planejamento prévio, imprescindível para a execução, controle e monitoramento de processos inerentes a sua função administrativa dentro de uma organização, abrangendo departamentos desde o setor produtivo, que está a cargo da gestão de matérias primas e bens da organização, ao setor de recursos humanos, que compactua com a gestão de relacionamentos pertinentes ao contexto empresarial entre colaboradores, e deste modo, tornando-se parte essencial do bom funcionamento dos processos da organização ligados à área administrativa.

\begin{abstract}
Logística Humanitária consiste de processos e sistemas envolvidos na mobilização de pessoas, recursos e conhecimentos para ajudar comunidades vulneráveis afetadas por desastres naturais ou emergências complexas. Ela busca a pronta resposta, visando atender o maior número de pessoas, evitar a falta e o desperdício, organizar diversas doações e, principalmente, atuar dentro de um orçamento limitado (MOURA, 2018, p. 18 apud NEVES, 2013, p.
\end{abstract}

165).

Nesse contexto, conforme explicitado acima, a prioridade máxima da logística humanitária: trata-se de assegurar a integridade física e cultural de um grupo ou comunidade, que se encontra em situação emergencial de risco. Nesse sentido, uma situação de risco se categoriza quando há a premissa de que a vida humana possa ser irremediavelmente prejudicada, o que pode se suceder devido a causas diversas, em especial, àquelas intrínsecas a fatores políticos, sociais e étnicos.

Nessa conjuntura, o termo "refugiado" apresenta destaque, uma vez que, segundo o art. $1^{\circ}$ da CONVENÇÃO RELATIVA AO ESTATUTO DOS REFUGIADOS (1951), estabelecido pelo $\mathrm{ACNUR}^{3}$, o termo "refugiado" se aplicará para pessoas que se encontram fora do seu país por causa de fundado temor de perseguição por motivos de raça, religião, nacionalidade, opinião política ou participação em grupos sociais, e que não possa, ou não queira, voltar para casa.

Dessa forma, tal grupo termina por se configurar como uma das problemáticas mais desafiadoras da logística humanitária, uma vez que, o risco atrelado a mobilização desses indivíduos é contínuo e possui múltiplas vertentes que ocorrem

\footnotetext{
${ }^{3}$ ACNUR é a sigla abreviada para Alto Comissariado das Nações Unidas para os Refugiados.
} 
de forma síncrona. Neste sentido, a Síria, por conta da desterritorialização ou apatrídia decorrente da exoneração defensiva de habitantes assediados pela guerra, os refugiados frequentemente encontram-se em posição de invisibilidade frente aos Estados acolhedores, acometidos à margem da sociedade, e destituídos de seus direitos civis.

Além disso, devido a questões legislativas, a condição de apátrida também atrasa o tempo de resposta do Estado frente às mazelas acometidas aos refugiados, sejam eles sírios ou de qualquer outra nacionalidade. Desse modo, causando o retardo do fluxo de pessoas exiladas que chegam no país, inclusive enfermos, idosos, mulheres grávidas e crianças, que devido ao transporte precário, efetuado muitas vezes através do modal marítimo e das condições da travessia, necessitam de auxílio médico urgente.

[...] é em 2016 - o ano em que, a pedido da União Europeia, a Turquia fechou o caminho mais curto e menos arriscado, e a rota de entrada mais longa e perigosa até a Turquia, ou até o Egito à Itália, se tornou a mais percorrida que foi gravado o maior número de mortes de refugiados, com cerca de 5096 estimadas a terem se afogado (FOUR DECADES OF CROSSMEDITERRANEAN UNDOCUMENTED MIGRATION TO EUROPE, 2017, p. 13, tradução nossa).

Em concordância com o ilustrado acima, no que toca ao modal de transporte utilizado para a travessia e às condições de viagem, relacionadas ao fluxo de pessoas: a travessia do Mediterrâneo é feita em botes ou em embarcações superlotadas, que não cumprem os requisitos mínimos de segurança, como a utilização de EPIs ${ }^{4}$, e realizada por meio do tráfico de pessoas, a custos altíssimos. Não obstante, mesmo ao alcançar com êxito o destino, não há garantia de sucesso no pedido de refúgio, o que ocasiona o regresso desses imigrantes, que não têm escolha a não ser tentar novamente.

Sendo assim, levando em consideração todas as adversidades confrontadas pelos refugiados, a assistência e suporte do ACNUR é imprescindível, já que, a ele é atribuído o dever de assegurar que qualquer pessoa, em caso de necessidade, possa exercer o direito de buscar e obter refúgio em outro país, além de garantir que os países estejam conscientes das suas obrigações. Ademais, é incumbido à logística humanitária atrelada aos países acolhedores, a tarefa de transportar, com segurança

\footnotetext{
${ }^{4}$ EPI é a sigla abreviada para Equipamentos de Proteção Individual.
} 
e qualidade, esses refugiados, independente de raça, religião, nacionalidade, opinião política ou participação em grupos sociais, de forma a endossar seu objetivo: garantir a preservação da vida humana.

\subsection{Tecnologia de Informação aplicada no Monitoramento dos Refugiados}

Dada a concepção adotada, o procedimento de busca de informações acerca dos meios tecnológicos e sua reverberação numérica utilizado foi bibliográfica: através da consulta em artigos e livros, além da sondagem de relatórios numéricos de órgãos internacionais ministrados pela União Europeia.

A TI evoluiu de uma orientação tradicional de suporte administrativo para um papel estratégico dentro da organização. A visão da TI como arma estratégica competitiva tem sido discutida e enfatizada, pois não só sustenta as operações de negócio existentes, mas também permite que se viabilizem novas estratégias empresariais (LAURINDO, 2001).

A Tecnologia de Informação, de abreviação TI exposta na citação anterior, tem se desenvolvido de maneira vultosa adquirindo novas funções e proporcionando a aquisição de novas informações em vários setores. No que tange às tecnologias logísticas aplicadas a supervisão de refugiados, a TI assume um papel ainda mais significativo, sua atuação através da Internet of Things (loT) e do Global Position System (GPS) simplifica o processo de obtenção de informações, melhorando o encadeamento logístico das operações.

O termo Internet das coisas $(I O T)$ pode ser definido como uma dimensão da internet atual, que facilita aos objetos do cotidiano se conectarem à internet, e assim, possibilitar uma conexão global, permitindo comandar esses objetos remotamente, segundo Li, Da Xu e Zhao (2015, apud SILVA, FREITAS e MONTEIRO, 2018).

Conforme explicitado acima, a Internet das coisas é uma tecnologia de monitoramento utilizada nos tempos atuais, com o objetivo de facilitar as conexões no mundo real. Nesse contexto, a utilização dessa ferramenta tecnológica, dada a sua dimensão global, é de fundamental uso na logística humanitária, ao monitorar o fluxo de pessoas em uma determinada região, como a União Europeia.

Ademais, segundo Silva, Freitas e Monteiro (2018:4), a Internet das coisas é apoiada pela utilização de sensores e de um sistema de $G P S^{5}$. Como na utilização da

\footnotetext{
${ }^{5}$ GPS é a sigla utilizada para abreviar Sistema de Posicionamento Global, na língua portuguesa.
} 


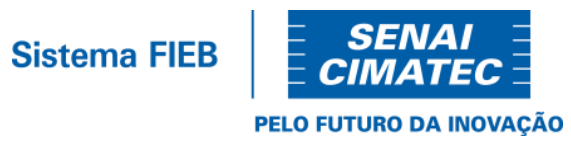

logística em apoio à prevenção de desastres, a partir da coleta de dados dos locais instalados.

Avaliar a importância dos pilares tecnológicos da loT, como mencionado anteriormente, é primordial para o melhor entendimento de sua eficiência. Além de compreender o fluxo de pessoas, analisar o uso dos sensores e do sistema de GPS é importante também para entender o funcionamento da cadeia de suprimentos em campos de refugiados, através do transporte de materiais essenciais.

Existem diferentes tipos de sensores e atuadores que controlam luz, temperatura e umidade e, ao controlar esses parâmetros, é possível melhorar o nível de conforto das pessoas nos ambientes controlados, o que pode ter um retorno positivo em termos de produtividade, enquanto reduzem os custos com aquecimento e resfriamento (RAGASUDHA, MAHESWARI e VENKATESH, 2017:48).

O autor afirma que a utilização de sensores na esfera logística, como demonstrado no trecho, traz vantagens com a produtividade com relação à eficiência na supervisão de bens transportados, como os suprimentos. Quanto aos materiais, em logística compreendidos como bens de suprimentos, é necessário haver um controle quanto à integridade desses bens no meio de transporte através do monitoramento da temperatura e de outros parâmetros que possam levar à danificação desses materiais.

Segundo Marino (2015:4-5), inicialmente criado com intuitos exclusivamente militares e gerido pelo Departamento de Defesa dos Estados Unidos, o Sistema GPS foi definitivamente aberto à utilização pública no ano 2000. E a partir dessa data ficou disponível para todos a capacidade de determinação da posição geográfica e de navegação entre quaisquer pontos da superfície terrestre. Ademais, foram colocados numa órbita a $20.200 \mathrm{~km}$ de altitude, e distribuídos por 6 planos orbitais diferentes para que qualquer ponto da superfície da Terra esteja, em qualquer momento, "em linha de vista" com pelo menos 4 satélites.

Dessa forma, considerando o GPS como um sistema de navegação via satélite capaz de fornecer informações corretas sobre a localização, tempo e distância de um dado alvo, no resgate a refugiados trata-se de uma ferramenta imprescindível. À medida que seu uso permite determinar a distância, a coordenada e o tempo que será necessário para se chegar ao local, é possível haver um planejamento de um resgate 


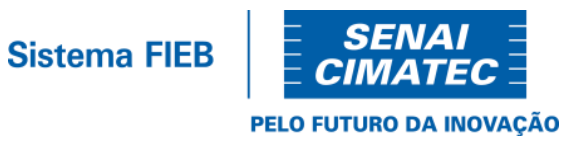

melhor idealizado, considerando outras variantes que possam inibir ou prejudicar o evento.

\subsection{Esforços da União Europeia}

O esforço para conter o fluxo migratório de refugiados realizado pela União Europeia é inegável. Devido a uma onda de conflitos, a Europa precisou enfrentar um afluxo sem precedentes de mais de um milhão de refugiados oriundos de regiões vizinhas em durante o período de 2015 a 2016 (COMISSÃO EUROPEIA, 2017). Diante dessa circunstancia inusitada, novos programas foram criados para instaurar a logística necessária visando uma melhora da qualidade de vida no continente europeu.

Ademais, a Comissão Europeia constata que a agenda europeia de migração foi criada inicialmente para dar subsidio aos imigrantes que tentavam chegar a Europa através do mar mediterrâneo e realocá-los temporariamente fornecendo proteção internacional para os mais necessitados. Posteriormente, a agenda criou formas mais efetivas de administrar o processo de migração através de um plano de ação que atua dentro, nas fronteiras e fora da União Europeia.

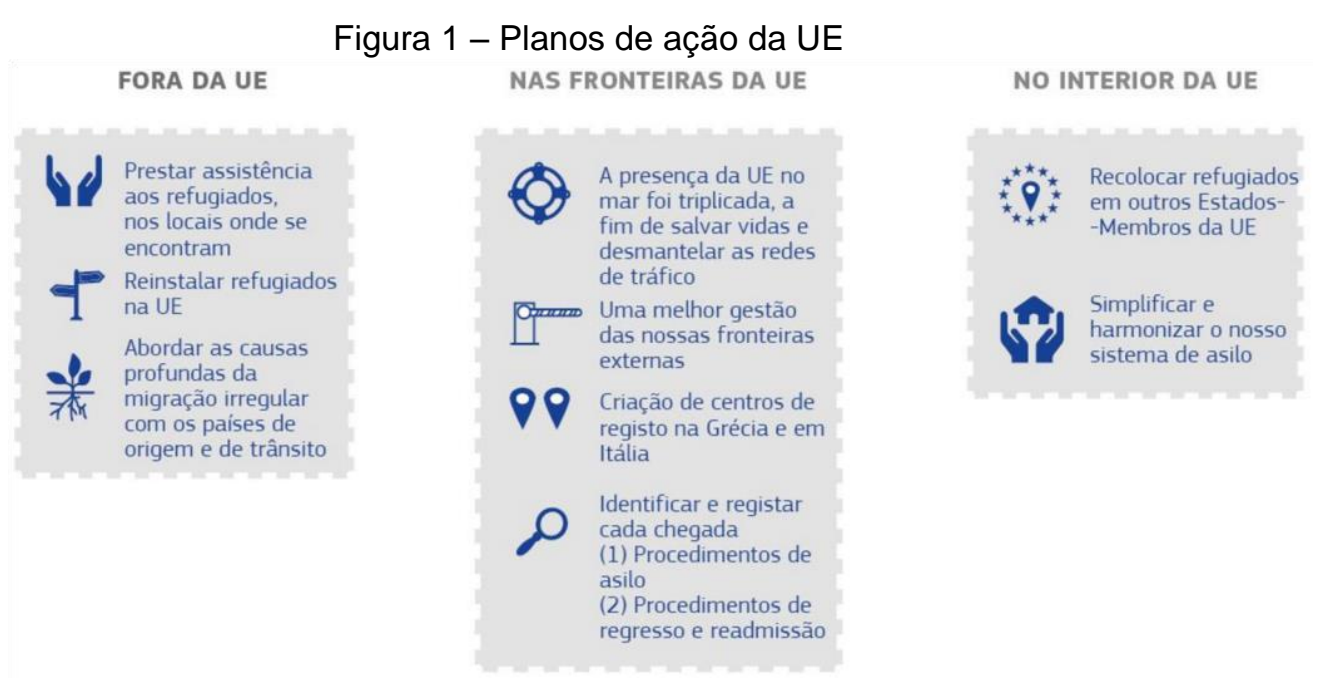

Fonte: Comissão Europeia (2017)

Ademais, é válido ressaltar o plano de ações da União Europeia. Como evidenciado acima, o bloco europeu conta com procedimentos logísticos fora, nas fronteiras e em seu interior, em ambas as partes é mostrado medidas com relação à proteção dos refugiados através principalmente do seu monitoramento constante. 


\section{MATERIAIS E MÉTODOS}

Esse artigo tem como metodologia uma finalidade básica estratégica, com ênfase em produzir um conhecimento útil com valia em estudos práticos, no que tange à contribuição que o estudo trará para a ciência. Nesse ponto, dirigir-se um tipo de pesquisa predominantemente descritiva e explicativa, cujo principal objetivo é explicar e racionalizar o objeto de estudo, com o intuito de expor as concepções de logística humanitária utilizada, além das tecnologias logísticas contemporaneamente utilizadas, e sobretudo buscar explicações acerca de suas funções nas operações encarregadas.

Nesse contexto, houveram preferências de quais fontes seriam dadas preferências para adentrar a fundamentação e sustentar os resultados para fomentação da discussão. Em primeiro plano, deu-se preferência por fontes dos últimos 5 (cinco), dada a complexidade do tema, ter um dimensionamento contemporâneo foi uma prioridade para concretização dos resultados. Outrossim, houve uma busca por artigos e livros da área de ciências humanas, área geral em que a logística se encontra, com o intuito de compreender as causas das problemáticas discutidas e o papel da eficiência da tecnologia nesse processo.

Ademais, é válido ressaltar o método da abordagem usado: quantitativa ao contextualizar com dados numéricos científicos a eficiência dessas tecnologias, através de técnicas e ferramentas estatísticas como meio de análise dos dados obtidos de agentes mundiais. Também é utilizado o método de abordagem qualitativo, ao caracterizar atribuições interpretativas de natureza subjetiva à análise do autor sustentada pela fundamentação teórica, ao buscar a partir de uma convicção com o intuito de provocar uma reflexão acerca da eficácia desses meios.

Dada a concepção adotada, o procedimento de busca de informações, acerca dos meios tecnológicos e sua reverberação numérica, utilizadas foi em maior parte bibliográfica: através da consulta em artigos e livros, dados esses usados no estudo sob forma de citações, servindo de embasamento para o desenvolvimento do assunto pesquisado, com ênfase ao artigo "Integração das práticas da logística humanitária, gestão de desastres e plano de auxílio mútuo" de MOURA.

Evidencia-se, também, um procedimento de busca documental, caracterizado pela união com a pesquisa bibliográfica criando um vínculo entre o discurso teórico e a realidade apresentada nos documentos não-científicos, através da sondagem de relatórios numéricos de órgãos internacionais, principalmente os relatórios da Comissão Europeia em 2017. 


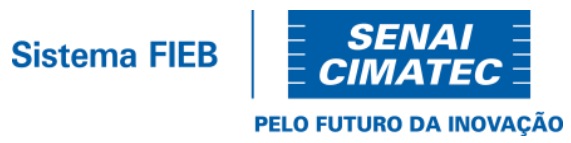

\section{RESULTADOS E DISCUSSÃO}

A partir das circunstâncias apresentadas, obteve-se como resultado crítico analítico da problemática em questão.

\subsection{Resultados}

A maneira em que os satélites estão distribuídos no espaço afeta de forma direta a qualidade e precisão do posicionamento. Nesse sentido, o DOP 6 trata-se do indicador que define o grau de exatidão do arranjo, demonstrando a propagação das falhas de observação nos critérios da estação em função da geometria da constelação.

Figura 2 - Quantidade de satélites visíveis na estação CHPG no dia 13 de agosto de 2015

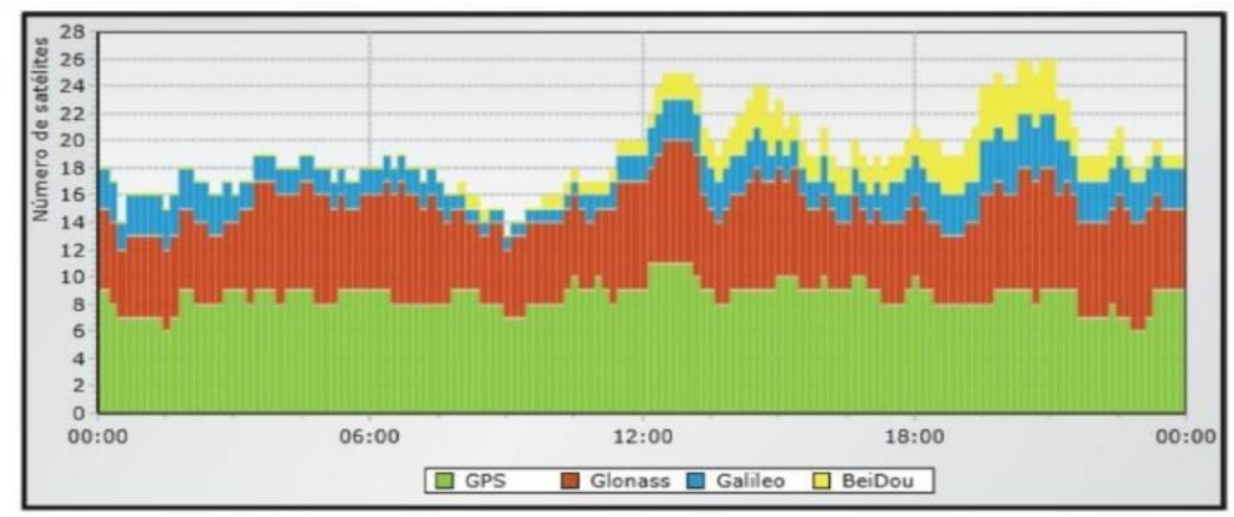

Fonte: FERREIRA (2016)

Até quatro satélites Galileo estiveram visíveis, contribuindo para um $\mathrm{PDOP}^{7}$ médio de 1,4, representando uma melhoria de $30 \%$, em relação ao obtido com o GPS e de 7\% em relação ao GPS estadunidense + GLONASS.

Figura 2 - Gráfico de redução da chegada de migrantes

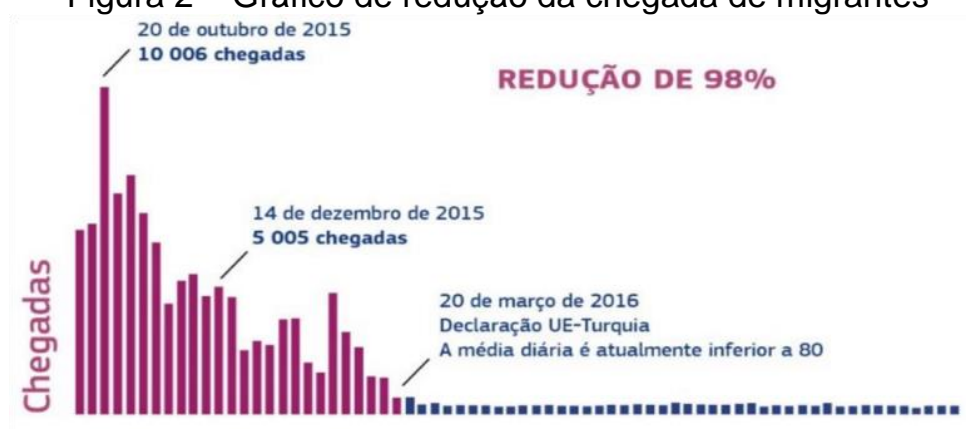

Fonte: Comissão Europeia (2017)

${ }^{6}$ DOP é a sigla análoga a Dilution of Precision, ou Diluição da Precisão, em português, e está normalmente associada a outras siglas, cumprindo a função de terminação.

7 PDOP é um indicador utilizado para mensurar a precisão de um satélite a partir de sua precisão em 3D. 
A nova Guarda Europeia de Fronteiras e Costeira foi lançada em outubro de 2016 a fim de permitir à Europa proteger as suas fronteiras externas comuns e enfrentar os novos desafios em matéria de migração e segurança em conjunto. Foram destacados mais de 1550 agentes para apoiar os Estados-Membros nas fronteiras externas, além dos atuais 100000 guardas de fronteira nos Estados-Membros.

\section{Tabela 1 - Fluxo aproximado de refugiados}

\begin{tabular}{cc}
\hline Quantidade & Período \\
\hline$\sim 918.000$ & 2015 \\
$\sim 110.000$ & 2019 \\
\hline
\end{tabular}

Fonte: Adaptado de Alto Comissariado das Nações Unidas para os Refugiados (2019)

\subsection{Discussões}

O sistema Galileo explicitado na Figura 2, que além de todas as qualidades já usufruídas de outros sistemas de posicionamento global, mais eficiente em comparação com o GPS estadunidense e do GLONASS russo, possui desde sua concepção um direcionamento para a utilização e operação civil, diferentemente do que ocorreu com os outros sistemas existentes, que tiveram sua origem associada ao uso militar. Não obstante, Galileo dispõe de 4 tipos de serviços operacionais: o OS ${ }^{8}$, voltado para o uso público e interesses gerais, possui uma exatidão que pode variar entre 15 metros na horizontal e 35 metros na vertical, para 4 metros na horizontal e 8 metros na vertical, dependendo do número de bandas via satélite utilizadas. O seu $C S$ ${ }^{9}$ que oferece maior performance em dados voltados ao serviço comercial e uso profissional que poderão ser acessados mediante contratação do serviço; o SOL ${ }^{10}$, que disponibiliza máxima qualidade para uso restrito, voltado às autoridades responsáveis pela proteção de civis e segurança nacional.

Dessa forma, em virtude dos fatos mencionados, a utilização do sistema GPS no contexto do monitoramento do fluxo de refugiados para União Europeia, trata-se de uma medida com potencial excepcional, uma vez que, por intermédio de Galileo, e em especial da opção operacional SOL, é possível firmar um plano de ação frente a problemática do deslocamento desses indivíduos por entre seus países de origem até a porta de entrada dos países membros da União, bem como controlar e tracejar as

\footnotetext{
${ }^{8}$ OS é uma sigla usada para abreviar Open Service, um serviço prestado por um satélite.

${ }^{9}$ CS é a sigla usada para abreviar Comercial Service, um serviço prestado por um satélite.

${ }^{10}$ SOL é a sigla usada para abreviar Safety of Life Service, um serviço prestado por um satélite.
} 
rotas que serão utilizadas, no menor tempo de locomoção, e com maior segurança possíveis, e que de outra forma, seriam muito custosos e/ou demandariam um maior tempo de planejamento, retardando sua execução.

Ademais, é válido ressaltar que os esforços da União Europeia, conforme demonstrado na Figura 3, têm mostrado resultados eficientes entre 2015 e 2016 no monitoramento do fluxo de refugiados pré e pós-refúgio nos locais em questão. A partir da Criação da Guarda Europeia de Fronteiras e Costeira se constatou uma redução de $98 \%$ da chegada de migrantes possibilitando a linearização do gráfico e sua estabilização. É válido ressaltar, inclusive, o papel do GPS europeu nesses índices, a partir do monitoramento do órgão agente em questão se pode verificar a quantidade aproximada de refugiados e propor novas medidas de controle.

Outrossim, também é importante analisar a Tabela $1 \mathrm{com}$ notoriedade entre 2015 e 2019 na queda significativa no índice logístico total de fluxo refugiados identificados, que dentre outros fatores, identifica-se principalmente uma trégua em conflitos em região de conflito nesse período, minimizando a quantidade de pessoas em busca de refúgio. Além disso, é válido traçar que com a evolução da loT e seus mecanismos de inteligência artificial, à medida que propõem a elaboração de dados mais transparentes, obtêm-se a consolidação de estratégias para barrar a entrada dessa modalidade de migração no bloco europeu. É notável também os fundamentos de logística humanitária nesse processo, a partir de uma situação emergente caracterizou-se uma necessidade na distribuição de suprimentos nesses locais, assegurando a integridade física desses seres humanos a partir de um controle mais efetivo.

\section{CONSIDERAÇÕES FINAIS}

Ao longo desse artigo foram abordados conceitos de Logística Humanitária, uma visão geral das consequências de se tornar um refugiado: a apatridia e os seus efeitos e causas inseridos no viés europeu. Além de ser discutido a utilização de tecnologias e métodos inovadores no exercício de monitoramento de refugiados na União Europeia, a partir de revisões dos mais diversos tipos de publicações acadêmicas, como artigos, teses e dissertações publicadas em sites oficiais de órgãos internacionais direcionados ao tema.

Ademais, a partir da análise do cenário referente ao fluxo de refugiados na União Europeia, dada a natureza excessiva de seu fluxo, sendo esta decorrente dos 
sucessivos conflitos que assolaram as proximidades do Mar Mediterrâneo e forçaram muitos indivíduos à exoneração. Além disso, com base nos dados adquiridos, validouse a eficiência de tecnologias como o GPS no monitoramento desses fluxos, bem como a evolução da loT e seu caráter fundamental para o bom funcionamento dessas tecnologias. Sob essa ótica, no que tange a União Europeia, verificou-se a existência do Galileo que Ihe confere uma posição privilegiada frente aos métodos e tecnologias do monitoramento de cargas e pessoas, uma vez que, trata-se de um sistema exclusivo e, em comparação com seus antecessores, possui diversas características ausentes em outros sistemas já desenvolvidos, o que representa suas potencialidades em relação a problemática abordada nesse artigo.

Por fim, observa-se que os objetivos da pesquisa em analisar a eficiência das tecnologias de monitoramento do afluxo de refugiados, bem como compreender suas fragilidades logísticas no fluxo do processo foram devidamente obtidos. Pode-se identificar as principais inovações relativas a problemática, bem como estabelecer um comparativo entre as tecnologias já existentes, e dessa forma, concluir que a utilização dessas técnicas no controle dos defluxos são de caráter imprescindível, uma vez que, através delas, é possível garantir que o maior número de imigrantes sobreviva ao trajeto e aos desafios de se tornar um refugiado. 


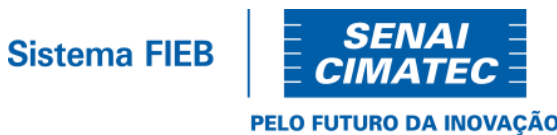

\section{REFERÊNCIAS}

Alto Comissariado das Nações Unidas para os Refugiados (org.). A UE e a Crise da Migração. 2017. Disponível em:

http://publications.europa.eu/webpub/com/factsheets/migration-crisis/pt/. Acesso em: 01 jun. 2020.

CARVALHO, Edison Alves de; ARAÚJO, Paulo César de. Noções básicas de sistema de posicionamento global GPS. 12. ed. Natal: Universidade Federal do Rio Grande do Norte, 2009. 244 p. Disponível em:

http://www.ead.uepb.edu.br/arquivos/cursos/Geografia_PAR_UAB/Fasciculos $\% 20 \%$ 20Material/Leituras_Cartograficas_II/Le_Ca_II_A08_MZZ_GR_260809.pdf. Acesso em: 15 maio 2020.

CARVALHO, José Crespo de. Logística. 3. ed. Lisboa: Edições Sílabo, 2002. 324 p.

Comissão Europeia (org.). A European Agenda on Migration. Bruxelas: [s.n.], 2015. 22 p. Disponível em:

https://ec.europa.eu/homeaffairs/sites/homeaffairs/files/what-we-

do/policies/european-

agendamigration/backgroundinformation/docs/communication_on_the_european_ag enda_on_migration_en.pdf. Acesso em: 01 jun. 2020.

Conselho da União Europeia (org.). Declaração UE-Turquia. 2016. Disponível em: https://www.consilium.europa.eu/pt/press/press-releases/2016/03/18/euturkeystatement/. Acesso em: 01 jun.2020.

EMPRESA BRASILEIRA DE PESQUISA AGROPECUÁRIA (Brasília). Ministério da Agricultura, Pecuária e Abastecimento do Brasil. Galileo: galileo positionig system. Galileo Positionig System. 2020. Disponível em: https://www.embrapa.br/satelitesdemonitoramento/missoes/galileo. Acesso em: 15 maio 2020.

ESTADOS UNIDOS DA AMÉRICA. ALTO COMISSARIADO DAS NAÇÕES UNIDAS PARA OS REFUGIADOS. Convenção sobre o Estatuto dos Apátridas. Nova lorque: Assembléia Geral das Nações Unidas, 1954. 13 p. Disponível em:

https://www.acnur.org/fileadmin/Documentos/portugues/BDL/Convencao_sobre_o_E statuto_dos_Apatridas_de_1954.pdf. Acesso em: 15 maio 2020.

EUROSTAT, Estatistics Explained. Estatísticas da Migração e da População Migrante. Genebra, 2017. 12p. Disponível em:

https://ec.europa.eu/eurostat/statistics-

explained/index.php?title=Migration_and_migrant_population_statistics/pt

FERREIRA, Samara Chamorro Navarro. Análise preliminar dos impactos do uso de mais de um sistema GNSS no posicionamento preciso. Revista Cartográfica, Rio de Janeiro, p. 31-51, 03 jun. 2016. Disponível em: www.revistasipgh.org. Acesso em: 29 maio 2020.

FFARGUES, Philipe. Four Decades of Cross-Mediterranean Undocumented 
Migration to Europe: a review of the evidence. Genebra: Organização Internacional da Migração, 2017. 46 p. Disponível em:

https://publications.iom.int/system/files/pdf/four_decades_of_cross_mediterranean.pd f. Acesso em: 15 maio 2020.

GONCALVES, Rafael Buchalla Garib; SAMED, Márcia Marcondes Altimari. Controle e Análise de Desperdício de Alimentos em um Restauramte. Trabalho de Conclusão de Curso do DEP, v. 13, n. 1, 2017.

LAURINDO, Fernando José Barbin et al. O papel da tecnologia da informação (TI) na estratégia das organizações. Gestão \& Produção, v. 8, n. 2, p. 160-179, 2001

MARINO, Tiago Badre. GPS: Sistema de posicionamento por satélites artificiais. Seropédica: Instituto de Agronomia Ufrrj, 2015. 56 p. Disponível em: http://www.ufrrj.br/lga/tiagomarino/aulas/7\%20-\%20GPS.pdf. Acesso em: 30 mai 2020.

MONTEIRO, V. L.; SILVA, I. T. S.; FREITAS, T. S.. Análise de Tecnologias da loT para Uso em Logística Humanitária de Busca e Salvamento de Pessoas. São José dos Campos. 12p. CIMATech, v. 1, n. 5, 2018.

MOURA, Eduardo Henrique de. Integração das práticas da Logística

Humanitária: gestão de desastres e plano de auxílio mútuo. Ponta Grossa:

Departamento de Engenharia Mecânica da Universidade Tecnológica Federal Paraná (utfpr), 2018. 72 p. Disponível em:

http://repositorio.roca.utfpr.edu.br/jspui/bitstream/1/12375/1/PG_DAMEC_2018_2_6. pdf. Acesso em: 15 maio 2020.

PEREIRA, Luciana Diniz Durães. Uma visão brasileira do conceito "refugiado ambiental". 60 anos de ACNUR, p. 221.

RAGASUDHA, S.; MAHESWARI, A.; VENKATESH, T. Internet of Things - A survey. Tamilnadu. 48p. IJATES, 2017. v. 5, n. 2, p. 44-50.

SUIÇA. ALTO COMISSARIADO DAS NAÇÕES UNIDAS PARA OS REFUGIADOS. Convenção Relativa ao Estatuto dos Refugiados. Genebra: Assembléia Geral das Nações Unidas, 1951. 21 p. Disponível em:

https://www.acnur.org/fileadmin/Documentos/portugues/BDL/Convencao_relativa_ao _Estatuto_dos_Refugiados.pdf. Acesso em: 15 maio 2020. 